\title{
Dentigerous Cysts of Maxillofacial Region- A Retrospective Clinico- Pathological Analysis of Patients at a Tertiary Care Centre in Central India
}

\author{
Karuna Jindwani ${ }^{1}$, Keshav Singh $^{2}$, Y. K. Paharia ${ }^{3}$, H. S. Markam ${ }^{4}$
}

\author{
${ }^{1}$ Department of Dentistry, Shyam Shah Medical College, Rewa, Madhya Pradesh, India. ${ }^{2}$ \\ Department of Medicine, Shyam Shah Medical College, Rewa, Madhya Pradesh, India. ${ }^{3}$ Department \\ of Dentistry, Gajra Raja Medical College, Gwalior, Madhya Pradesh, India. ${ }^{4}$ Department of \\ Dentistry, Netaji Shuhash Chandra Bose Medical College, Jabalpur, Madhya Pradesh, India.
}

\section{ABSTRACT}

\section{BACKGROUND}

Dentigerous Cyst (DC) is a common type of cyst encountered in oral cavity. These types of cysts are usually found covering the crowns of unerupted teeth and expand in size due to collection of cystic fluid in the region of dental follicle. They can be treated by marsupialisation or enucleation of the lesion based on the involvement of the lesion with the adjacent structures. We wanted to analyze the demographic distribution, clinical, and radiographic features of DC cases reporting to the dental department at NSCB Medical College, Jabalpur (M.P.).

\section{METHODS}

A retrospective study of clinical, radiographic presentation and management of 13 cases of DC attending OPD of Department of Dentistry and treated by enucleation and marsupialization, at Netaji Subhash Chandra Bose (NSCB) Medical College at Jabalpur (M.P.) from July 2016 till December 2017 was conducted.

\section{RESULTS}

Out of 13 cases 8 patients (61.53\%) were males and 5 (38.46\%) were females. Wide variation in age was seen (14-47 years). 8 (61.53\%) patients had a lesion in mandible and was most commonly associated with mandibular third molar which was encountered in 5 cases $(38.46 \%)$. Most common presenting symptom was a swelling which was found in $76.92 \%$ patients. 9 cases $(69.23 \%)$ were treated with enucleation and marsupialisation was used to treat 4 cases $(30.76 \%)$.

\section{CONCLUSIONS}

A male: female ratio of 1.6:1 was reported showing a slight male dominance. DC most commonly involved unerupted mandibular third molars. The prognosis of patients treated with enucleation and marsupialisation is satisfactory.

\section{KEY WORDS}

Dentigerous Cyst, Odontogenic Cyst, Retrospective, Enucleation, Marsupialisation
Corresponding Author: Dr. Karuna Jindwani, Associate Professor Department of Dentistry, Shyam Shah Medical College, Rewa-486001, Madhya Pradesh, India. E-mail: jindwanikaruna@yahoo.co.in

DOI: $10.14260 / \mathrm{jemds} / 2020 / 329$

Financial or Other Competing Interests: None.

How to Cite This Article: Jindwani $K$, Singh $K$, Paharia $Y K$, et al. Dentigerous cysts of maxillofacial region- $a$ retrospective clinico- pathological analysis of patients at a tertiary care centre in Central India. J. Evolution Med. Dent. Sci. 2020;9(18):1509-1514, DOI: 10.14260/jemds/2020/329

Submission 01-01-2020,

Peer Review 16-04-2020,

Acceptance 23-04-2020,

Published 04-05-2020.

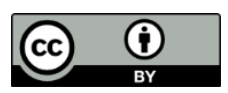




\section{BACKGROUND}

According to Kramer, a cyst is never physiological. It is nothing but a pathological cavity which may contain fluids, semi-fluids and gasses but not by collection of pus de novo. [1, 2] Many of the DCs are lined by epithelium.[1,2] They are most commonly found in oral cavity because of ubiquitous presence of epithelial cells during the presence of tooth formation.[2,3] Any of the odontogenic cyst needs to be promptly managed and diagnosed as some variants i.e. keratocysts are aggressive and subject to recurrence. ${ }^{[4]}$

Dentigerous cysts (DCs) are commonly occurring odontogenic cysts and fall second in the list after periapical radicular cysts, accounting for nearly $20-24 \%$ of all the cysts seen in oral and maxillofacial region. [5] The etiology as reported in literature associates these cyst in relation to the crown of an unerupted or impacted teeth which grows in size due to collection of fluid in the space created between the reduced enamel epithelium and the enamel of the involved tooth which in turn leads to the expansion of its follicle.[6] As mentioned, DCs always involve an unerupted tooth or a developing tooth bud and occur mostly around the crown of the impacted mandibular $3^{\text {rd }}$ molars, followed, in order of frequency, by the maxillary canines, maxillary $3^{\text {rd }}$ molars and, rarely, the maxillary central incisors. ${ }^{[7]}$ They have a classical slow growing tendency and that too occurs at the cost of the expansion of the cortices of the jaws.[8] The cyst may manifest in the form of swelling, displacement of the teeth, mobility of teeth and sensitivity if it acquires a size larger than $2 \mathrm{~cm}$ in diameter.[9] Radiographically, they usually show a welldefined unilocular radiolucency, often with a sclerotic border surrounding the crown of an unerupted tooth. [7] DCs are usually dormant pathologies which are frequently coincidentally discovered while taking radiographs for formulation of a differential diagnosis of a failure of a tooth to erupt, a missing tooth or malalignment. However, due to the slow growing and dormant (asymptomatic) nature, these lesions can reach a marked size if they are not diagnosed early and promptly treated on time and methodically.[10] Moreover, if prompt management is not instituted these cysts may weaken up the bone leading to fracture of the jaw pathologically, further impaction of the permanent tooth, bone deformities, and grave sequelae in the form of benign odontogenic tumours like ameloblastoma or malignancies as squamous cell carcinoma or mucoepidermoid carcinoma. ${ }^{[11,12,13]}$ Hence, to avoid gross destruction, fracture and deformation of bone, early diagnosis and prompt management of these cysts is essential.[14] More than one DCs occurring concomitantly are really rare and exclusively associated with syndromes or systemic ailments such as mucopolysaccharidosis and cleidocranial dysplasia.[15,16]

The gold standard for treating any cystic cavity lies in enucleation of the entire cystic lining and its contents. However, for a DC, the treatment modalities range from either surgical removal of the cyst, avoiding damage to the involved permanent tooth, or enucleation of the cyst along with the removal of the involved tooth, or de-roofing the cyst by marsupialization technique.[17] Marsupialization is the treatment of choice, for DC involving favorably positioned unerupted teeth to contemplate for a smooth uneventful eruption of underlying teeth. However, for long standing large lesions with teeth in unfavorable position; enucleation of the cyst along with removal of offending teeth remains the gold standard. [14] Management of DC in primary and mixed dentitions needs special consideration for meticulous preservation of the developing permanent tooth buds.

Hence, the present study was undertaken to analyze the demographic distribution, clinical and radiographic features of DC cases reporting to the dental department at NSCB Medical College, Jabalpur (M.P.) from July 2016 till December 2017. This study will not only help the general practitioners to know about the biologic behavior of DC which is required for their early detection and treatment but also throws light on future research.

\section{METHODS}

This retrospective study was conducted from July 2016 to December 2017 in the Department of Dentistry at NSCB Medical College, Jabalpur (M.P.). The present study involved the records of 13 consecutive patients operated for the treatment of DC. The entire database was collected after clearance from institutional ethic committee from the case files, imaging and histopathology reports and follow-up records to analyze the following information: age at the time of analysis, gender of the patient, location of the lesion, involved teeth, presenting symptoms, surgical treatment modalities and treatment outcomes and follow up. Radiographical analysis was based on a pre-operative CT scan or orthopantomogram which was advised for all patients to determine the extent of lesion. 9 cases (69.23\%) were treated by elective enucleation and marsupialisation was done in 4 cases $(30.76 \%)$. The diagnosis was confirmed after biochemical analysis of aspirated fluid and excised specimen was sent for histopathological analysis. Regular follow up was done after 7 days postoperatively, then after 1 month, 6 months, and 12 months subsequently.

\section{Statistical Analysis}

The Statistical Package for Social Science \{SPSS Version 20 will be used for Data Analysis. Mean, median, and SD are used to describe quantitative data. Qualitative data are summarized using frequency and percentage.

\section{RESULTS}

From July 2016 to December 2017 there were 13 cases of DC, reporting in the dental department at NSCB Medical College, Jabalpur. Out of 13 patients 8 patients $(61.53 \%)$ were males and 5 (38. 46\%) were females (Table 1). Males outnumbered females with a male: female ratio of 1.6:1. A wide variation was observed in age distribution, ranging from 14 to 47 years. The second and the third decades of life were most frequently reported in the present study (Table 2). Among the 8 DCs affecting the mandible, 5 cases were associated with the mandibular angle, posterior body or ramus region with the $3^{\text {rd }}$ molar as the associated tooth; followed by 3 cases involving the anterior mandibular region involving impacted mandibular canine. However, in the case of maxillary arch, 2 cases were found in the maxillary posterior 
region associated with maxillary $3^{\text {rd }}$ molar teeth and 3 cases involved then maxillary anterior region with maxillary canine as the associated teeth (Table 3 ). The chief complaint in $76.92 \%$ (10) of the patients was found to be swelling of the affected area of jaws and $61.53 \%$ (8) of the patients had intermittent episodes of pain along with recurrent swelling. Other commonly encountered complaints comprised of tooth mobility and root resorption in 4 patients (30.76\%), pus discharge in 3 patients (23.07\%), and displacement of associated teeth in 9 patients $(69.23 \%)$. The floor of the maxillary sinus was seen displaced in two cases $(15.38 \%)$ and in 2 cases $(15.38 \%)$ involving the mandible, inferior alveolar nerve was found displaced in orthopantomographs (Table 4). The patients were regularly followed up subsequent to the surgical management. The minimum follow up was of six months. Enucleation was the treatment used in 9 patients (69.23\%) involving removal of the tooth involved in the lesion and 4 patients (30.76\%) were treated with marsupialization where the tooth was allowed to erupt on its own in the younger age group patients (Table 5). Reoccurrence was not reported in any case during frequent follow ups after surgery in our study.

\begin{tabular}{|ccccc|}
\hline Sl. No. & & Gender & Number & \% Age \\
1. & & Males & 08 & 61.53 \\
2. & Females & 05 & 38.46 \\
& Total & & 13 & 100 \\
\hline \multicolumn{4}{|c|}{ Table } & 1. Gender-Wise Distribution of Patients $(\mathbf{n}=\mathbf{1 3})$ \\
\hline
\end{tabular}

\begin{tabular}{|cccc|}
\hline Sl. No. & Decades & Number & \% Age \\
1. & $10-19$ yrs. & 04 & 30.76 \\
2. & $20-29$ yrs. & 04 & 30.76 \\
3. & $30-39$ yrs. & 03 & 23.07 \\
4. & $40-49$ yrs. & 02 & 15.38 \\
& & 13 & 100 \\
\hline \multicolumn{4}{|c|}{ Table 2. Age-Wise Distribution of Patients (n=13) } \\
\hline \multicolumn{4}{|c|}{} \\
\hline
\end{tabular}

\begin{tabular}{|cccc|}
\hline Sl. No. & Associated Tooth & Frequency & \% Age \\
1. & Maxillary third molars & 05 & 38.46 \\
2. & Maxillary canine & 03 & 23.07 \\
3. & Mandibular canine & 03 & 23.07 \\
4. & Maxillary third molar & 02 & 15.38 \\
& Total & $\mathbf{1 3}$ & $\mathbf{1 0 0}$ \\
\hline \multicolumn{4}{c}{ Table 3. Frequency Distribution of Involved Teeth } \\
\hline
\end{tabular}

\begin{tabular}{|cccc|}
\hline Sl. No. & Presenting Symptoms & Cases & \% Age \\
1. & Swelling & 10 & 76.92 \\
2. & Pain & 08 & 61.53 \\
3. & Tooth mobility & 04 & 30.76 \\
4. & Pus discharge & 03 & 23.07 \\
5. & Teeth displacement & 09 & 69.23 \\
6. & Root resorption & 04 & 30.76 \\
7. & Displacement of maxillary sinus & 02 & 15.38 \\
8. & Displacement of inferior alveolar nerve & 02 & 15.38 \\
\hline \multicolumn{4}{|c|}{ Table 4. Summary of Presenting Symptoms } \\
\hline
\end{tabular}

\begin{tabular}{|cccc|}
\hline Sl. No. & Treatment Modality & No. of Patients & \% Age \\
1. & Enucleation & 9 & 69.23 \\
2. & Marsupialisation & 4 & 30.76 \\
& Total & 13 & 100 \\
\hline \multicolumn{4}{|c|}{ Table 5. Treatment Modalities Adopted $(\mathbf{n}=\mathbf{1 3})$} \\
\hline
\end{tabular}

\section{DISCUSSION}

The oral and maxillofacial region displays the presence of a large number of cysts when compared to any other parts of the body. Odontogenic cysts are very commonly managed in routine dental practice. However, it constitutes a major aspect of dental sub specialities like oral pathology and oral surgery. DCs are the second most common cysts of odontogenic origin after periapical radicular cysts.[18] DC contributes to nearly $16.6 \%$ of all odontogenic lesions.[19]

These cysts can broadly be classified into two varieties as reported in literature: development and inflammatory cysts. It is stated that the development type of DC is formed around the crown of an unerupted tooth by accumulation of fluid either between the reduced enamel epithelium and the enamel or in between the layers of the enamel organ. This fluid accumulation occurs due to the force exerted by an erupting tooth on an impacted follicle which obstructs the venous flow and thereby induces rapid transudation of serum across the capillary wall.[18,20,21] The other school of thought of origin of developmental type of DC states that DC originates due to the destruction of forming cells of the follicle after delayed eruption.[18,21,22] The collection of the debris during this destruction results in an increased osmotic tension and hence cyst formation.

As far as the inflammatory type of DC is considered it is presumed to originate from the overlying nonvital necrotic deciduous tooth, as suggested by Bloch. [2, 18, 23] The exact pathogenesis of DC is still not known; however most authors favor a developmental origin. It encloses the crown of an unerupted, impacted or supernumerary tooth and grows in size by expansion of its follicle and which usually is attached to its neck.[2,4]

DCs are the second most common type of cysts in the jaws after radicular cysts; therefore knowledge on the prevalence and relative distribution and also their signs and symptoms, imaging and histopathological findings may help the practitioners to achieve to a clear clinical diagnosis and hence plan the management accordingly. The frequency of DCs in the literature, in studies with at least 50 DCs reported, varied from $9 \%$ to $38 \%$.[24,25,26]

DC is usually is seen in the patients in their second and third decades of life.[26,27,28,29] Similar to the previous studies, ${ }^{[4,10,30]}$ In the present study the age of incidence of DC ranged from 14 to 47 years and a peak incidence of DC was recorded during the second and third decades of life, but some others like Jones et al though reported a wide age range and a peak incidence during the $5^{\text {th }}$ decade. [31]

Similar to male preponderance suggested in other studies, males had a slightly higher incidence of DCs than females with a male: female ratio of 1.6:1.[15,28] This finding is similar to that in previous studies. $[1,5,29,32]$ The reason for this gender prediction is not clear. Daley et al suggested that it might be related to a smaller jaw size and a greater tendency for prophylactic extraction of third molars in females. ${ }^{[5]}$ It might be considered that men are more likely to neglect their hygiene and to have trauma of maxillary anterior teeth. ${ }^{[5]}$

DC is most commonly associated with mandibular third molars followed by maxillary canines, mandibular second premolars and maxillary third molars in decreasing order of frequency. [5] In our study the most common site of occurrence of DC was the mandibular third molar (38.46\%) in 5 patients which was in consensus with other studies in literature. $[3,18,26,28,30]$ Although Tortorici et al,[26] reported the preferential involvement of DC in the anterior maxillary region and Waldron $\mathrm{CA}^{[33]}$ found the upper third molars to be the most prevalent site. In the present study DC was not commonly found in association with mandibular third molars 
in 5 cases $(38.46 \%)$ and in maxillary arch, maxillary canine was the associated tooth in 3 cases $(23.07 \%)$. This may not be a surprising finding given the fact that lower third molars and upper canines are teeth most commonly affected by impaction. Although DCs are highly prevalent odontogenic cysts, bilateral occurrence of these cysts is not very frequent. Multiple DCs are associated with Maroteaux-Lamy (mucopolysaccharidosis, type VI) syndrome and cleidocranial dysplasia that have been reported in literature.[15,16,34,35] However, the present cases were of normal non-syndromic patients.

Since, majority of these cysts are asymptomatic, they are frequently discovered as an incidental finding on radiographs when these are taken because a tooth has failed to erupt or a tooth is missing, or because teeth are not aligned.[36] Radiographically, majority of DC appear as well delineated unilocular homogenous radiolucency enveloping the crown of an unerupted tooth, where the radiolucency starts from the cementoenamel junction at the neck of the tooth, but, some are multilocular.[36,37] These variants of DC namely central, lateral and circumferential have been described. In the central variety the crown is enveloped symmetrically. The dilatation of the follicle on one aspect of the crown results in lateral variety of the cyst. In a circumferential cyst the entire tooth appears to be enveloped by the cyst. [1] A large DC may appear as multilocular owing to the persistence of bone trabeculae within the radiolucency.[38] In the absence of infection, most DC show well corticated margins, this is thin and smoothly curved. The buccal or labial plate expansion is common but bicortical expansion is extremely rare. ${ }^{[37]}$ DCs also have a greater tendency than other jaw cysts to resorb the roots and displace not only the involved tooth but also the adjacent ones. ${ }^{[1,37]}$ These findings are consistent with the results of the present study as swelling due to expansion of buccal/labial plate was found in 10 patients $(76.92 \%)$ and teeth displacement was seen in 4 patients in $69.23 \%$ patients and root resorption was seen in 4 patients $(30.76 \%)$. The orthopantomogram is the chief imaging procedure to track the cysts. The CT scan is currently more demanded. It is considered as the best imaging procedure to assess the size of the cyst and the position relative to the dental nerve and the dental apices. Both the investigation techniques were liberally used in our study. However, a radiograph does not differentiate between the various types of lesions which are associated with the unerupted teeth.[23] Therefore, FNAC and histopathologic examination of the cyst contents and lining is a must for final diagnosis. In the non-inflamed DC, a 2-4 cell layer thick primitive type of thin epithelial lining of cuboidal or low columnar cells may be present. The fibrous connective tissue wall consists of loose connective tissue stroma which is rich in acid mucopolysaccharides. In inflamed DC, the fibrous cyst wall shows an inflammatory infiltrate.[21] Moreover, the epithelial cells lining the lumen of the DC possess an unusual ability to undergo metaplastic transformation. Rarely, some untreated DCs develop into odontogenic tumor (e.g. ameloblastoma) or a malignancy (e.g. oral squamous cell carcinoma).[21,39] To avoid such complications, marsupialization and surgical enucleation of the cyst lining may be the treatment of choice. Treatment of DC varies depending on the size, location, and extent of the lesion. Large cystic lesions often require variable bone removal to ensure total removal of cyst mandibulectomies are exceptional, even in the case of very big cysts. [4]If the cyst is small, the enucleation in one piece is the rule. If the path of eruption is favourable, effort should be made to allow the involved tooth to erupt.[40,41] Marsupialization, decompression, and the Partsch operation, all refer to creating a surgical window in the wall of the cyst, and maintaining continuity between the cyst and the oral cavity or maxillary sinus or nasal cavity. [21] The post-surgical healing of the osseous defects is rapid among pediatric patients due to their potentiality for bone regeneration and repair. [40,41]

In our study, 4 cases (30.76\%) of large cysts in pediatric patients or the ones in proximity to vital structures were treated by marsupialisation. All the four teeth erupted to their functional position either or their own or with orthodontic treatment. Cyst enucleation along with extraction of the impacted tooth was done in rest of the 9 patients $(69.23 \%)$ for the following reasons when-

- The formation of the tooth was complete.

- The eruption time of the involved permanent tooth was exceeded by more than 2 years.

- The impacted tooth was unlikely to be useful.

- There was lack of adequate space of eruption due to deep impactions and overlapping, when even orthodontic up righting was not possible.

- There was lack of adequate space to accommodate the tooth in the arch.

The prognosis of both the treatment modalities was good, with no reoccurrence seen in any of the cases.

\section{CONCLUSIONS}

The old adage, "a stitch in time saves nine" holds true especially for early diagnosis, as well as timely and proper management of DC, to avoid its transformation into mural ameloblastomas, mucoepidermoid carcinomas or grave metaplastic transformation as reported in this study. The results of our study are as follows-

- DC has a male predilection with peak incidence during the second and third decades of life.

- The most commonly affected site is the mandibular third molar region followed by maxillary canine region.

- Expansion of the buccal/labial cortical plate is more common leading to swelling.

- The prognosis of enucleation and marsupialisation was satisfactory according to the size of the lesion.

A thorough understanding of the nature of the lesion backed by good clinical history and radiograph can go a long way in helping the clinician to arrive at the correct diagnosis so as to alleviate the problem and ameliorate the condition in the best long term interests of the suffering patients.

The results obtained from the present study are derived from a small sample population. Hence, further research with large sample size and longer duration of the study are necessary to arrive at a definite conclusion. 


\section{REFERENCES}

[1] Shear M, Speight PM. Cysts of the oral and maxillofacial regions. $4^{\text {th }}$ edn. Oxford: Blackwell Munkrgaard Publishing 2007: p. 59-78.

[2] Sridevi K, Kaushik A, Ramaswamy P, et al. Dentigerous cysts of maxillofacial region- clincal, radiographic and biochemical analysis. Kathmandu Univ Med J 2015;13(49):8-11.

[3] Koseoglu BG, Atalay B, Erdem MA. Odontogenic cysts: a clinical study of 90 cases. J Oral Science 2004;46(4):2537.

[4] Meningaud JP, Oprean N, Arnop PP, et al. Odontogenic cysts: a clinical study of 695 cases. J Oral Sci 2006;48(2):59-62.

[5] Daley TD, Wysocki GP, Pringel GA. Relative incidence of odontogenic tumors and oral and jaw cysts in a Canadian population. Oral Surg Oral Med Oral Pathol 1994;77(3):276-80.

[6] Ikeshima A, Tamura Y. Differential diagnosis between dentigerous cyst and benign tumor with an embedded tooth. J Oral Sci 2002;44(1):13-7.

[7] Ziocardi VB, Eggless TE, Schnider RE. Using fenestration technique to treat a large dentigerous cyst. J Am Dent Assoc 1997;128(2):201-5.

[8] Benn A, Altini M. Dentigerous cysts of inflammatory origin. A clinicopathological study. Oral Surg Oral Pathol Oral Radiol Endod 1996;81(2):203-9.

[9] Bonder L, Woldenberg Y, Bar-Ziv J. Radiographic features of large cysts lesions of jaws in children. Pediatr Radiol 2003;33(1):3-6.

[10] Ochsenius G, Escobar E, Goday L, et al. Odontogenic cysts: analysis of 2,944 cases in Chile. Med Oral Pathol Oral Cir Bucal 2007;12(2):E85-91.

[11] Chakraborty A, Sarkar S, Dutta BB. Localised disturbances associated with primary teeth eruption. J Indian Soc Pedod Prev Dent 1994;12(1):25-8.

[12] Stuart CW, Michael JP. Oral radiology - Principles and interpretation. $6^{\text {th }}$ edn. Philadelphia: Mosby 2011.

[13] Houston GD. Oral Pathology. Ameloblastoma arising in a dentigerous cyst. J Okla Dent Assoc 2007;98(9):28-9.

[14] Farah CS, Savage NW. Pericoronal radiolucencies and the significance of early detection. Aust Dent J 2002;47(3):262-5.

[15] Shah N, Thuau H, Beale I. Spontaneous regression of bilateral dentigerous cysts associated with impacted mandibular third molars. Br Dent J 2002;192(2):75-6.

[16] Ustuner E, Fitoz S, Ataroy C, et al. Bilateral maxillary dentigerous cysts: a case report. Oral Surg Oral Med Oral Pthol Oral Radiol Endod 2003;95(5):632-5.

[17] O'Neil DW, Mosby EL, Lowe JW. Bilateral mandibular dentigerous cyst in a five year old child: report of a case. ASDC J Dent Child 1989;56(5):382-4.

[18] Manickam S, Mandana D, Praveen SB. Analysis of 153 cases of odontogenic cysts in a south Indian sample population: a retrospective study over a decade. Braz Oral Res 2012;26(4):330-4.

[19] Kreidler JF, Rabenheimer EJ, van Heerden WF. A retrospective analysis of 367 cystic lesion of the jaw the Ulm experience. J Craniomaxillofac Surg 1993;21(8):339-41.
[20] Main DM. The enlargement of epithelial jaw cyst. Odontol Revy 1970;21(1):21-9.

[21] Kirtaniya BC, Sachdev V, Singla A, et al. Marsupiliation: a conservative approach for treating dentigerous cyst in children in the mixed dentition. J Indian Soc Pedod and Prev Dent 2010;28(3):203-8.

[22] Toller PA. The osmolarity of fluid from the cyst of jaws. Br Dent J 1970;129(6):275-8.

[23] Bloch JK. Dentigerous cyst. Dent Cosmet 1928;70:70811.

[24] Bartaineh AB, Rewashideh MA, AL-Qudah MA. The prevalence of inflammatory and developmental odontogenic cysts in a Jordanian population: a clinicopathologic study. Quintessence Int 2004;35(10):815-9.

[25] Mosqueda-Taylor A, Irigoyen-Camacho ME, Diaz-Franco MA, et al. Odontogenic cysts. Analysis of 856 cases. Med Oral 2002;7(2):89-96.

[26] Tortorici S, Amidio E, Massenti MF, et al. Prevalence and distribution of odontogenic cyst in Sicily: 1986-2005. J Oral Sci 2008;50(1):15-8.

[27] Neville BW, Damn DD, Allen DD, et al. Odontogenic cysts and tumors. In: Neville BW, Damn DD, Allen DD, et al. eds. Oral and maxillofacial pathology. $3^{\text {rd }}$ edn. St. Louis: Saunders Elsevier 2009: p. 678-740.

[28] Zhang LL, Yang R, Zhang L, et al. Dentigerous cyst: a retrospective clinicopathological analysis of 2082 dentigerous cysts in British Columbia, Canada. Int J Oral Maxillofac Surg 2010;39(9):878-82.

[29] Ramesh G, Dave A, Nanda KDS, et al. Dentigerous cyst involving multiple teeth in non-syndromic patients and cholesterol granuloma - a review. Int J Oral and Maxillofac Pathol 2010;1(1):13-6.

[30] Lin HP, Wang YP, Chen HM, et al. A clinicopathologic study of 338 dentigerous cysts. J Oral Pathol Med 2013;42(6):462-7.

[31] Jones AV, Craig GT, Franklen CD. Range and demographics of odontogenic cyst diagnosed in a UK population over a 30 - year period. J Oral Pathol Med 2006;35(8):500-7.

[32] Ochensius G, Escobar E, Godoy L, et al. Odontogenic cysts: analysis of 2,944 cases in Chile. Med Oral Pathol Oral Cir Buccal 2007;12(2):E85-91.

[33] Waldron CV. Odontogenic cysts and tumors. In: Neville BW, Damn DD, Allen CM, et al. eds. Oral and maxillofacial pathology. $2^{\text {nd }}$ edn. Philadelphia: W. B. Saunders 2002: p. 493-540.

[34] Roberts MW, Barton NW, Constentopoulas G, et al. Occurrence of multiple dentigerus cysts in a patient with Maroteaux-Lamy syndrome (mucopolysacchariodosis, Type VI). Oral Surg Oral Med Oral Pathol 1984;58(2):169-75.

[35] Trimble LD, West RA, Mc-Neill RW. Cleidocranial dysplasia: comprehensive treatment of dentofacial abnormalities. J Am Dent Assoc 1982;105(4):661-6.

[36] White SC, Pharoah MJ. Cyst and cyst like lesions of the jaws. In: White SC, Pharoah MJ, eds. Oral radiology: principles and interpretation. $6^{\text {th }}$ edn. St. Louis, MO: Mosby Elsevier 2009: p. 346-50. 


\section{Jemds.com}

[37] Farman AG, Nortje CJ, Wood RE. Panoramic radiology of pericoronal pathoses. In: Panoramic radiology. $1^{\text {st }}$ edn. Springer 2007: p. 143.

[38] Shafer, Hine, Levy. Shafer's Text book of oral pathology. $6^{\text {th }}$ edn. Elsevier India 2009: p. 254-8.

[39] Slootweg PJ. Carcinoma arising from reduced enamel epithelium. J Oral Pathol 1987;16(10):479-82.

[40] Zakirulla M, Yavagai CM, Jayashankar DN, et al. Dentigerous cyst in children: a case report and outline of
Original Research Article

clinical management for pediatric and general dentists. J Orofac Res 2012;2(4):238-42.

[41] Tournas AS, Tewfik MA, Chauvin PJ, et al. Multiple unilateral maxillary dentigerous cysts in a nonsyndromic patient: a case report and review of the literature. International J Pediatr Otorhinolaryngol Extra 2006;1(2):100-6. 